\title{
Microstructure Evolution of Mg-Gd-Y-Zn-Zr Magnesium Alloy During Partial Remelting
}

\author{
Jianquan $\mathrm{TAO}^{1}{ }^{*}$, Xinghua $\mathrm{JI}^{2}$, Yanping ZHANG ${ }^{1}$, Changjian SUN ${ }^{1}$, Tianquan DENG ${ }^{1}$ \\ ${ }^{1}$ National Defence Research and Application Center of Precision Plastic Forming Technology, Chongqing 400039, China \\ ${ }^{2}$ Laiwu Vocational and Technical College, Laiwu 271100, China
}

crossref http://dx.doi.org/10.5755/j01.ms.20.4.6483

Received 18 February 2014; accepted 03 November 2014

\begin{abstract}
The article deals with the research on the microstructure evolution of Mg-Gd-Y-Zn-Zr magnesium alloy through partial remelting process. It aims at finding out what effects the microstructure of semi-solid Mg-Gd-Y-Zn-Zr alloy will result in under different remelting temperatures and holding times. Based on the results, if to raise the remelting temperature and to prolong the holding time, the size of solid grain will tend to expand and its spheroidization degree also begins to show improvement. In addition, the grain shows tendency of coarsening when the holding time increases.

Keywords: microstructure, semi-solid, Mg-Gd-Y-Zn-Zr alloy.
\end{abstract}

\section{INTRODUCTION}

Researchers begin to show more and more concerns on the applications of magnesium alloy in the fields of aerospace technology, automotive and electronics industries. As a lightweight structure material, magnesium alloy is less dense, stiff with high specific strength compared to other alloys [1-4]. But the current situation is that magnesium alloys are still not widely used because of their hexagonal closed-packed crystal structure, compared with titanium alloys [5-8]. Semi-solid state forming is recognized as a relatively new method for collecting products almost net shaped. For instance, alloys can be acquired under the semisolid condition $[9,10]$.The microstructure of starting materials treated in such a way are required to be in the form of spheroid, instead of the form of dendrite under the state of semi-solid $[11,12]$. At present there are several methods recognized to be capable of meeting the relative requirements, such as SIMA (short for strain induced melt activation), SSTT (short for semi-solid thermal transformation) RAP (short for recrystallization and partial melting) and grain refinement [13-17].

There are many reports on the magnesium alloys microstructure evolution in the semi-solid state. Z. D. Zhao et al [18] studied how the SSTT route and RAP route would affect the microstructure evolution of thixo-forged ZK60-Y magnesium alloys respectively. As the holding time increases, they observed an increase of the solid grain size for the semi-solid alloy produced through the routes of SSTT and the RAP. Besides, ZK60-Y alloy produced through the SSTT route shoes obvious sign of coalescence, while the ZK60-Y alloy produced through RAP route shows obvious Ostwald ripening. X. H. Du et al [19] studied what mechanical properties AZ91D magnesium alloy forming through semi-solid die-casting has, as well as its process of microstructure evolution. Q. Chen et al. [20] studied the developing process of microstructure and

\footnotetext{
*Corresponding author. Tel.: +86-23-68792232, fax: +86-23-68792100. E-mail address: jarryallen@163.com (J. Q. Tao)
}

thixo-extrusion of magnesium alloy produced through repetitive upsetting-extrusion. They found that grain began to coarsen due to the prolonged holding time, and meanwhile its degree of spheroidization also improved. What's more, grains of spheroidal solid would form better when the heating temperature increased.

However, in current literature, researches on how the microstructure of semi-solid Mg-Gd-Y-Zn-Zr magnesium alloy evolves during partial remelting are not many, though the microstructure's evolving process of semi-solid is a key factor to determine the properties of alloys. So, the present paper aims to study the microstructure's evolving process of $\mathrm{Mg}-\mathrm{Gd}-\mathrm{Y}-\mathrm{Zn}-\mathrm{Zr}$ alloy through the adoption of the process of semi-solid partial remelting. Besides, the paper also studies how the microstructure of $\mathrm{Mg}-\mathrm{Gd}-\mathrm{Y}-\mathrm{Zn}-\mathrm{Zr}$ alloy during partial remelting will change under different holding times and remelting temperatures.

\section{EXPERIMENTAL PROCEDURE}

The alloy used in the present study is composed of the following chemical components: Mg-8.38 wt.\%-Gd2.59 wt.\%-Y-2.56 wt.\%-Zn-0.46 wt.\%-Zr. The first step is to cut the Mg-Gd-Y-Zn-Zr alloy formed by extrusion into several samples, and it should be ensured that the diameter of the samples is $2 \mathrm{~mm}$, while the height is $12 \mathrm{~mm}$. The samples are heat treated in a furnace with $\mathrm{Ar}$ as the protective atmosphere. The heating temperatures are set between the solidus and liquids temperature, with the holding time ranging for $5 \mathrm{~min}$ to $30 \mathrm{~min}$. The samples must be quenched in cold water soon after their being removed from the furnace.

The microstructure evolution during reheating is examined by optical microscopy (OM). The ways of conventional mechanical polishing and etching are adopted to prepare the samples. The etching solution is composed by $100 \mathrm{ml}$ ethanol, $6 \mathrm{~g}$ picric acid, $5 \mathrm{ml}$ acetic acid and $10 \mathrm{ml}$ water. The method of mean linear intercept is adopted to measure the grain sizes of the reheated samples. 


\section{RESULTS AND DISCUSSION}

\subsection{Effects of holding time on the microstructure of Mg-Gd-Y-Zn-Zr alloy during partial remelting}

Fig. 1 presents the optical micrograph of original extruded Mg-Gd-Y-Zn-Zr alloy. The average grain size is $22 \mu \mathrm{m}$. Fig. 2 is a representation about the microstructure evolving process of extruded Mg-Gd-Y-Zn-Zr alloy after partial remelting at $550^{\circ} \mathrm{C}$, and the remelting time is divided into four different time spans, including 5 minutes, 10 minutes, 20 minutes and 30 minutes, respectively.

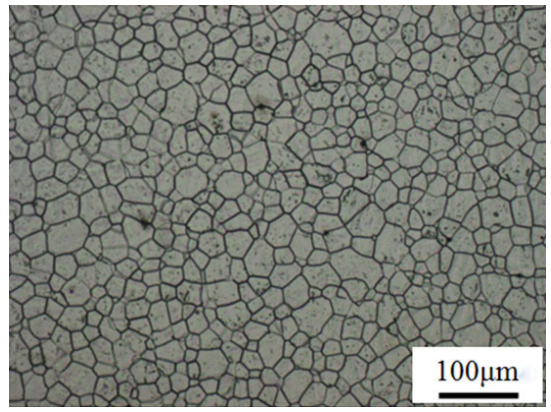

Fig. 1. The microstructure of original extruded Mg-Gd-Y-Zn-Zr alloy

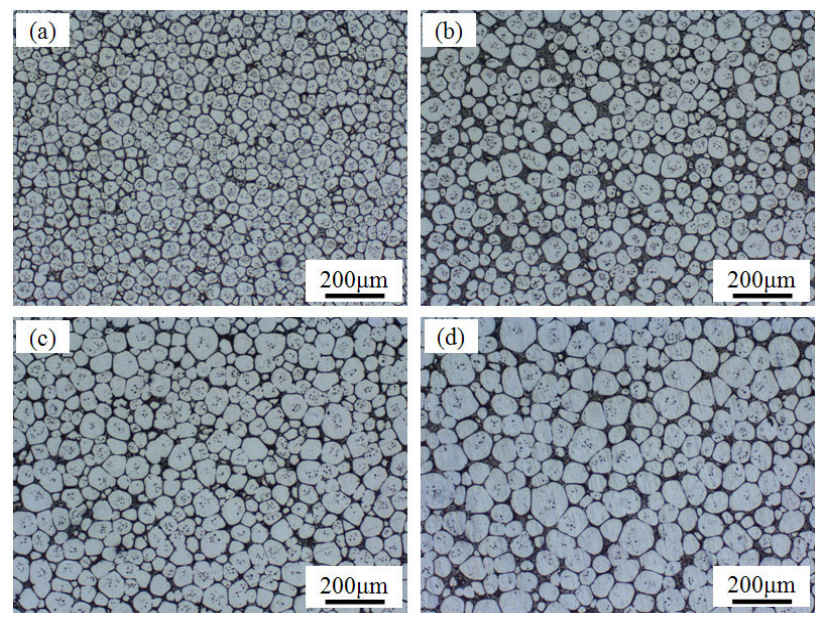

Fig. 2. The microstructure of samples reheated at $550{ }^{\circ} \mathrm{C}$ after different holding time: $\mathrm{a}-5 \mathrm{~min}, \mathrm{~b}-10 \mathrm{~min}, \mathrm{c}-20 \mathrm{~min}$, $\mathrm{d}-30 \mathrm{~min}$

When the heating temperature for alloy is slightly higher than that of solid phase temperature, due to the dissolution of low melting point phase, the boundaries of grain are penetrated by degrees through liquid phase. At the same time, the solid phase spheroidization and grains coarsening are activated when the liquid phase occurs in the grain boundaries (Fig. 2, a). In the initial stages of holding remelt temperatures, the non-uniform temperature field often causes non-uniform distribution of the liquid. It helps to propel the liquid penetration [18]. Under the condition that the holding time was prolonged to 10 minutes, microstructure test results show that the polygon particles begins to show the degree of spheroidization, which is apparent (Fig. 2, b).When to prolong the holding time to as long as 20 minutes, it was obvious that the grain began to coarsen under the state of semi-solid (Fig. 2, c). Also, it can be seen that the grain boundaries began to disappear caused by coalescence, as in Fig. 2, c. The disappearance of grain boundaries between A grain and B grain could be seen. These resulted in that a larger anomalous shaped grain was formed. When the holding time further increased to 30 minutes, because of the adjacent grains coalescence, grain coarsening phenomenon occurred (Fig. 2, d).
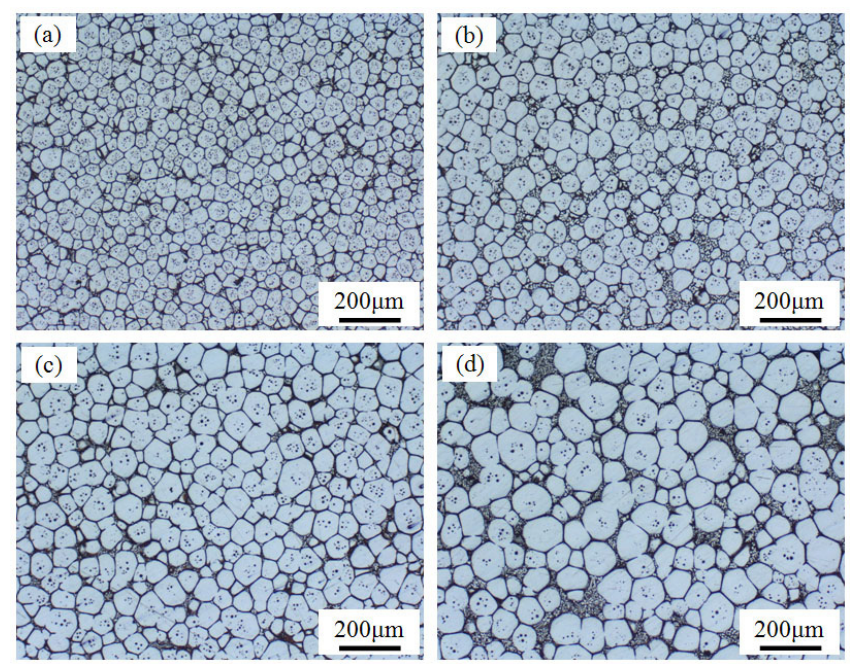

Fig. 3. The microstructure of samples reheated at $560^{\circ} \mathrm{C}$ after different heating times: $\mathrm{a}-5 \mathrm{~min}, \mathrm{~b}-10 \mathrm{~min}, \mathrm{c}-20 \mathrm{~min}$, $\mathrm{d}-30 \mathrm{~min}$

Figure 3 shows the extrusion Mg-Gd-Y-Zn-Zr alloy microstructure evolution during partial remelting at $560^{\circ} \mathrm{C}$, and the holding time is divided into four different time spans, including 5 minutes, 10 minutes, 20 minutes, 30 minutes, respectively. Recrystallization occurs fully, and nearly perfect spherical recrystallization grains with uniform distribution of liquid droplets (Fig. 3, a). The solid grains coarsen slightly with the prolonging of holding time. The grain begins to coarsen under the state of the semisolid at holding time of $10 \mathrm{~min}$; the liquid phase among solid grain boundaries becomes thicker with the increasing of holding time by comparing among Fig. 3, a-d.

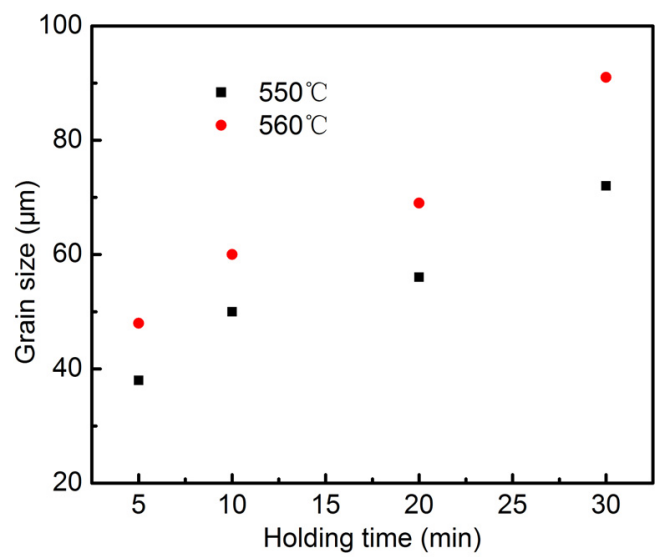

Fig. 4. The grain size of samples after partial remelting at $550{ }^{\circ} \mathrm{C}$ and $560^{\circ} \mathrm{C}$ for different holding times

Fig. 4 is the grain size of the Mg-Gd-Y-Zn-Zr alloy after partial remelting under $550^{\circ} \mathrm{C}$ and $560^{\circ} \mathrm{C}$ with the different time spans of holding time. With holding time prolonged at $550^{\circ} \mathrm{C}$ and $560^{\circ} \mathrm{C}$, the grain size shows a continuous increase. Compared with the remelting temperature of $560^{\circ} \mathrm{C}$, the $\mathrm{Mg}-\mathrm{Gd}-\mathrm{Y}-\mathrm{Zn}-\mathrm{Zr}$ alloy shows finer solid grains at $550^{\circ} \mathrm{C}$. 


\subsection{Effects of temperatures on the microstructures of Mg-Gd-Y-Zn-Zr during partial remelting}

Fig. 5 is a representation on the microstructure of semi-solid Mg-Gd-Y-Zn-Zr alloy partially remelted under different remelting temperatures. From Fig. 2 and Fig. 3, at $20 \mathrm{~min}$ holding time, the nearly perfect spherical recrystallization grains with uniform distribution of liquid droplets. So, for all remelting temperatures, the holding time is $20 \mathrm{~min}$. The morphology shows that the remelting temperature has a great influence on the microstructure of samples after remelting. The balling phenomenon does not completely occurred at $540^{\circ} \mathrm{C}$ remelting temperature. However, spheroidizing traces are found at the grain boundaries (Fig. 5, a). The grain boundaries obviously had been melted and the solid phase particles gradually grow up at $550^{\circ} \mathrm{C}$ (Fig. 5, b) and $560^{\circ} \mathrm{C}$ (Fig. 5, c) remelting temperatures. The adjacent liquid phase surrounded the solid phase. As the heating temperature increased to $570^{\circ} \mathrm{C}$, an obvious growing up of solid phase particles is seen, while the increase of liquid phase can also be seen(Fig. 5, d). With increasing the melting temperature, at the grain boundaries, the low melting point particles melt and liquid phases increase gradually.

The solid particle melt and the solid particle gradually change to a globular grain at $550{ }^{\circ} \mathrm{C}$ heating temprature. And, adjacent solid particles contact with each other and form a bigger grain by solid-solid agglomeration and some liquid at grain boundaries will be entrapped into the grains with the increasing of the melting temperature, at $560{ }^{\circ} \mathrm{C}$ and $570{ }^{\circ} \mathrm{C}$ heating tempratures, for example. So, in the microsturcture of $550^{\circ} \mathrm{C}$ heating temprature, amount of liquid is more than three microstructures.

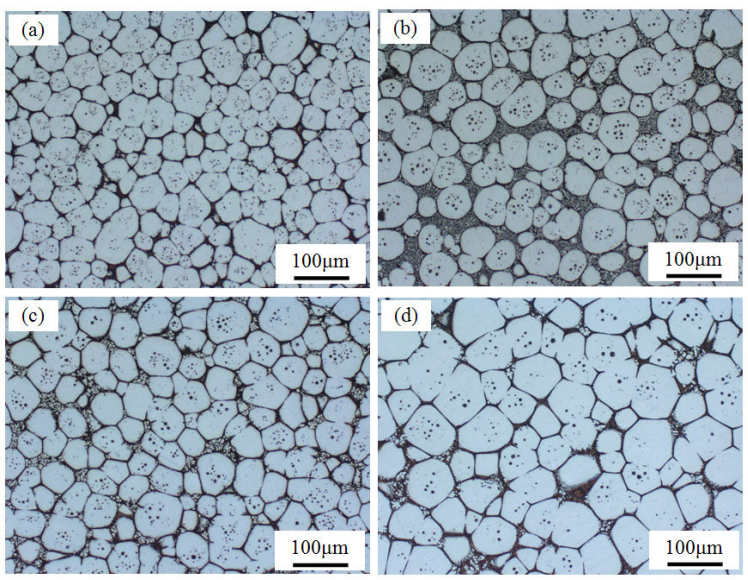

Fig. 5. The microstructure of samples after reheating for $20 \mathrm{~min}$ at different heating temperatures: $\mathrm{a}-540^{\circ} \mathrm{C}, \mathrm{b}-550^{\circ} \mathrm{C}$, c $-560{ }^{\circ} \mathrm{C}, \mathrm{d} 570{ }^{\circ} \mathrm{C}$

Fig. 6 shows the grain size of semi-solid Mg-Gd-Y$\mathrm{Zn}-\mathrm{Zr}$ alloy partially remelted with the changing of remelting temperature. As can be seen, if to raise the remelting temperature, the grain size continues to increase. The average grain size increases from $42 \mu \mathrm{m}$ at $540{ }^{\circ} \mathrm{C}$ to $75 \mu \mathrm{m}$ at $570^{\circ} \mathrm{C}$. Fig. 7 shows the solid fraction of semisolid Mg-Gd-Y-Zn-Zr alloy at different heating temperatures. It can be seen from Fig. 7 that the solid fraction were $0.65\left(540^{\circ} \mathrm{C}\right), 0.50\left(550^{\circ} \mathrm{C}\right), 0.56\left(560^{\circ} \mathrm{C}\right)$ and $0.58\left(570^{\circ} \mathrm{C}\right)$, respectively.

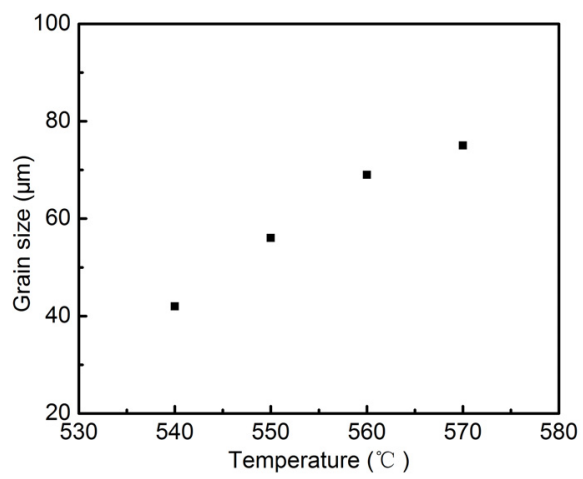

Fig. 6. The grain size evolution during partial remelting at different temperatures

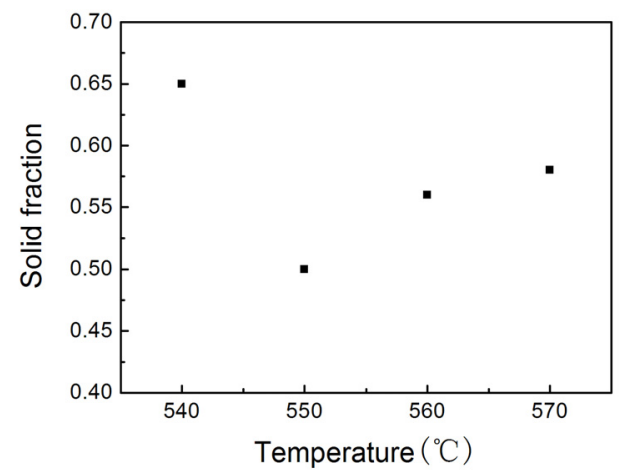

Fig. 7. The solid fraction of Mg-Gd-Y-Zn-Zr alloy at different heating temperatures

\subsection{Mechanism analysis for the change of solid particle shape}

Fig. 8 shows a principle diagram for the change of liquid film and solid particle size during partial remelting. (a)
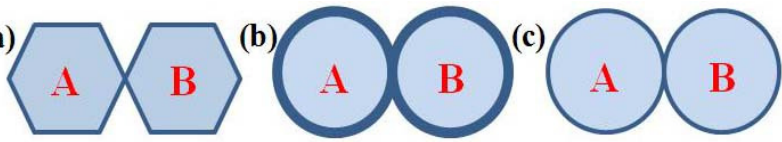

(d)
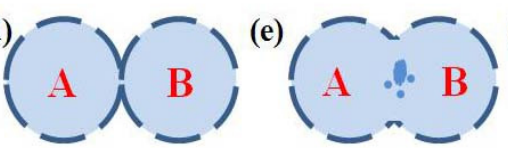

(f)

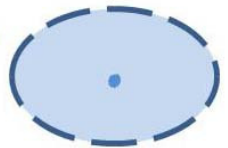

Fig. 8. Principle diagram of the change of solid particles shape during partial remelting

The recrystallized grains (A and B) are surrounded by continuous liquid film (as Fig. 8, a, has presented). When the holding time increases, solid particles gradually become globular (Fig. 8, b). The surface curvature of grains and its relation with the decreasing of equilibrium melting point can give an explanation on how the spheroidal grains form. The solid surface curvature's influenced under the equilibrium melting point can be represented as:

$\Delta T_{r}=-\frac{2 \sigma T_{M} V_{S} \kappa}{\Delta H}$,

where $\sigma$ is the surface tension; $T_{M}$ is a balanced transition temperature; $V_{S}$ refers to the solid volume; $\kappa$ refers to the mean surface curvature; $\Delta H$ refers to the solid and liquid molar enthalpy change; $\Delta T_{r}$ in the above equation is 
positive; $\Delta T_{r}=T_{M}-T$ refers to the decrease in equilibrium melting point .

It is obvious that the sharp-angles of the solid particle melt and the solid particle gradually change to a globular grain (Fig. 8, b). If to prolong the holding time, the phases of liquid and solid will be in the condition of dynamic equilibrium. After the process of grain spheroidization has finished, the grain coarsening will result in the thickness decreasing of liquid film (Fig. 8, c). If the holding time increases further, liquid film becomes thinner. Continuous liquid film gradually becomes discontinuous (Fig. 8, d). In the condition that adjacent solid particles (A and B) contact with each other and form solid-solid grain boundaries, the growth of solid particle is controlled by solid-solid agglomeration instead of by diffusion. The agglomeration between adjacent grains leads to a decreased shape factor because of the formation of "neck". During the agglomeration of adjacent grains, some liquid at grain boundaries will be entrapped into the grains (Fig. 8, e). With a prolonging in holding time, mass transport provides the diffusion of atoms for the region of the "neck" between two adjacent grains and the irregular grain forms (Fig. 8, f).

\section{CONCLUSIONS}

In the process of partial remelting, if to raise the remelting temperature and to prolong the holding time, the solid grain size of $\mathrm{Mg}-\mathrm{Gd}-\mathrm{Y}-\mathrm{Zn}-\mathrm{Zr}$ magnesium alloy also begins to increase, while the spheroidizing degree show tendency of being improved. Meanwhile, the formation speed of liquation also increased slightly. Increase remelting temperature is helpful to obtain semi-solid globular structure. It also helps to reduce the possibility of calescence, which may happen among solid grains. But to prolong the holding time may also cause the grains to coarsen.

\section{REFERENCES}

1. Chen, Q., Huang, Z. W., Zhao, Z. D., Shu, D. Y. First Principles Study on Elastic Properties, Thermodynamics and Electronic Structural of AB2 Type Phases in Magnesium Alloy Solid State Communications 162 2013: pp. 1-7.

2. Czerwinski, F. Size Evolution of the Unmelted Phase During Injection Molding of Semisolid Magnesium Alloys Scripta Materialia 48 (4) 2003: pp. 327-331.

3. Chen, Q., Huang, Z. W., Zhao, Z. D., Hu, C. K., Shu, D. Y. Thermal Stabilities, Elastic Properties and Electronic Structures of B2-MgRE (RE = Sc, Y, La) by First-principles Calculations Computational Materials Science 67 2013: pp. 196-202.

4. Czerwinski, F. The Generation of Mg-Al-Zn Alloys by Semisolid State Mixing of Particulate Precursors Acta Materialia 52 (17) 2004: pp. 5057-5069.

5. Chen, Q., Lin, J., Shu, D. Y., Hu, C. K., Zhao, Z. D., Kang, F., Huang, S. H., Yuan, B. G. Microstructure Development, Mechanical Properties and Formability of Mg-Zn-Y-Zr Magnesium Alloy Materials Science and Engineering A 554 (30) 2012: pp. 129-141. http://dx.doi.org/10.1016/j.msea.2012.06.025

6. Li, D. N., Luo, J. R., Wu, S. S., Xiao, Z. H., Mao, Y. W., Song, X. J., Wu, G. Z. Study on the Semi-solid Rheocasting of Magnesium Alloy by Mechanical Stirring Journal of Materials Processing Technology $129(1-3) \quad$ 2002: pp. $431-434$.
7. Chen, Q., Yuan, B. G., Zhao, G. Z., Shu, D. Y., Hu, C. K., Zhao, Z. D., Zhao, Z. X. Microstructural Evolution During Reheating and Tensile Mechanical Properties of Thixoforged AZ91D-RE Magnesium Alloy Prepared by Squeeze Casting-solid Extrusion Materials Science and Engineering A 537 2012: pp. 25-38.

8. Ramadan, M., Takita, M., Nomura, H. Effect of Semisolid Processing on Solidification Microstructure and Mechanical Properties of Gray Cast Iron Materials Science and Engineering $A 417$ (1-2) 2006: pp. 166-173.

9. Nafisi, S., Emadi, D., Ghomashchi, R. Semi Solid Metal Processing: The Fraction Solid Dilemma Materials Science and Engineering $A 507(1-2)$ 2009: pp. 87-92.

10. Seo, P. K., Park, K. J., Kang, C. G. Semi-solid Die Casting Process with Three Steps Die System Journal of Materials Processing Technology 153-154 2004: pp. 442-449.

11. Chowdhury, J., Ganguly, S., Chakraborty, S. Implications of Solid Phase Interaction Mechanisms on Momentum, Heat and Solute Transport in Semi-solid Materials Processing International Journal of Heat and Mass Transfer 50 (13) 2007: pp. 2692-2703.

12. Chen, Q., Luo, S. J., Zhao, Z. D. Microstructural Evolution of Previously Deformed AZ91D Magnesium Alloy During Partial Remelting Journal of Alloys and Compounds 477 (1-2) 2009: pp. 726-731.

13. Bolouri, A., Kang, C. G. Correlation Between Solid Fraction and Tensile Properties of Semisolid RAP Processed Aluminum Alloys Journal of Alloys and Compounds 516 (5) 2012: pp. $192-200$ http://dx.doi.org/10.1016/j.jallcom.2011.12.045

14. Meng, Y., Sugiyama, S., Yanagimoto, J. Microstructural Evolution During RAP Process and Deformation Behavior of Semi-solid SKD61 Tool Steel Journal of Materials Processing Technology 212 (8) 2012: pp. 1731-1741. http://dx.doi.org/10.1016/j.jmatprotec.2012.04.003

15. Nami, B., Shabestari, S. G., Miresmaeili, S. M., Razavi, H., Mirdamadi, S. The Effect of Rare Earth Elements on the Kinetics of the Isothermal Coarsening of the Globular Solid Phase in Semisolid AZ91 Alloy Produced via SIMA Process Journal of Alloys and Compounds 489 (2) 2010: pp. $570-575$. http://dx.doi.org/10.1016/j.jallcom.2009.09.112

16. Zhao, Z. D., Chen, Q., Hu, C. K., Huang, S. H., Wang, Y. Q. Near-liquidus Forging, Partial Remelting and Thixoforging of an AZ91D+Y Magnesium Alloy Journal of Alloys and Compounds 485 2009: pp. 627-636. http://dx.doi.org/10.1016/j.jallcom.2009.06.053

17. Zhang, L., Liu, Y. B., Cao, Z. Y., Zhang, Y. F., Zhang, Q. Q. Effects of Isothermal Process Parameters on the Microstructure of Semisolid AZ91D Alloy Produced by SIMA Journal of Materials Processing Technology 209 (2) 2009: pp. $792-797$. http://dx.doi.org/10.1016/j.jmatprotec.2008.02.046

18. Zhao, Z. D., Chen, Q., Chao, H. Y., Huang, S. H. Microstructural Evolution and Tensile Mechanical Properties of Thixoforged ZK60-Y Magnesium Alloys Produced by Two Different Routes Materials Design 31 (4) 2010: pp. 1906-1916.

19. Du, X. H., Zhang, E. Microstructure and Mechanical Behaviour of Semi-solid die-casting AZ91D Magnesium Alloy Materials Letters $61 \quad(11-12) \quad 2007$ : pp. $2333-2337$.

20. Chen, Q., Zhao, Z. D., Zhao, Z. X., Hu, C. K., Shu, D. Y. Microstructure Development and Thixoextrusion of Magnesium Alloy Prepared by Repetitive Upsettingextrusion, Journal of Alloys and Compounds 509 (26) 2011: pp. $7303-7315$. http://dx.doi.org/10.1016/j.jallcom.2011.04.113 